\title{
Analysis of Power Grid Corporation's supply chain carbon management
}

\author{
Zhang Xiaoxuan ${ }^{1, a^{*}}$, Xue Song ${ }^{1, b}$ \\ ${ }^{1}$ State Grid Energy Research Institute, Beijing 102209, China

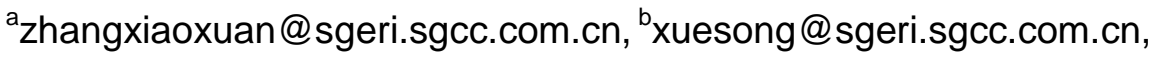

Keywords: supply chain carbon management, power Grid Corporation, carbon emission reduction, carbon market.

\begin{abstract}
As an important part of energy industry, power grid plays a pivotal and irreplaceable role in promoting low-carbon development. In this paper, under the perspective of supply chain carbon management, the pathways of power grid corporation's carbon emissions reduction were discussed, including decreasing line loss, promoting clean energy development, and so on. Considering the development of national carbon market, the paper analyzes the impact on power grid corporation and put forward some suggestions.
\end{abstract}

\section{Introduction}

Under the background of global responding to climate change and effort towards sustainable development of energy and environment, low carbon development has become a new mode of world economic development and the inevitable choice of many countries for the future. U.S., EU, Japan, India and many other countries have put out some relevant policies to promote low-carbon economic development [1].

The Chinese government is vigorously promoting the national energy saving and carbon emission reduction. In November 2009, China proposed the emission reduction target that $\mathrm{CO}_{2}$ emission of per unit GDP will be reduced by $40 \%$ to $45 \%$ in 2020 relative to the 2005 . In the 12 th Five-Year Plan, carbon trading mechanisms is explicitly to be launched initially as pilot projects in order to explore the establishment of carbon emissions trading market. China has conducted seven ETS pilots (Shenzhen, Beijing, Tianjin, Shanghai, Guangdong, Hubei, Chongqing) and the size of market as well as the level of activity is in the world-leading status. The development of national market has been put on the agenda. It is planned to be built in 2017, will cover iron and steel, electricity, chemicals, building materials, paper and non-ferrous metals and other key industries. On 30 June 2015, the Chinese government submitted its Intended Nationally Determined Contribution (INDC), detailing its commitment to climate change mitigation and adaptation for the post-2020 period. The specific goals such as carbon dioxide emissions per unit of GDP will lower 60\% to $65 \%$ from 2005 levels and peak carbon dioxide emissions will be achieved by approximately 2030 or sooner as best efforts allow are put forward[2].

In China, the power sector is the largest source of emissions, account for more than $40 \%$ of $\mathrm{CO}_{2}$ emission nationwide. In all seven polite markets, power generation companies are the companies under control. As a member of power industry, power grid companies are also facing great pressure to reduce emissions. In order to promote emission reduction, the power grid companies should first analysis the pathways of carbon emissions reduction, including its own carbon emission reduction opportunities and other emissions reduction opportunities in the supply chain. 


\section{The supply chain carbon management of power grid corporation}

The electric supply chain includes generators, grid and consumers. Power generators cause direct emissions while generating energy. Grid connects power generators and consumers, serve and promote carbon emission reduction of generation side and consumer side[3]. Consumers, as the end of the electricity supply chain, their behaviors of consumption have a significant impact on the emissions.

Under the perspective of supply chain carbon management, a corporation should find and evaluate carbon emission reduction potential in terms of the value chain, including the emission reduction benefits achieved by itself and the benefits achieved by the cooperation with upstream and downstream supply chain[4]. Grid connects power generators and consumers, serve and promote carbon emission reduction of generation side and consumer side. So, power grid corporation's carbon reduction potential is mainly reflected in two aspects: one is the emissions reduction potential can achieve by itself, another is the emissions reduction potential that can be achieved by cooperation with the generations and customers in the supply chain, serving as a platform of energy-electricity transmission and optimizing resources allocation.

The carbon emissions reduction potential achieved by power grid corporation include the reduction of transmission and distribution losses, and the recovery and substitution of sulfur hexafluoride $\left(\mathrm{SF}_{6}\right)$. power grid corporation try hard to reduce power transmission and distribution losses, that will contribute to construct smart grid, optimize network structure, develop UHV transmission technology, and so on. The UHV transmission lines significantly decrease the transmission losses. Taking Xiangjiaba - Shanghai $\pm 800 \mathrm{kV}$ UHV DC as an example, comparing to conventional $\pm 500 \mathrm{kV}$ DC projects, the transmission loss rate per unit distance decreased by $50 \%$ [5]. With the development of smart control technologies and continuously improvement of management level, the line loss rate will decline further. $\mathrm{SF}_{6}$ is a kind of good dielectric gas which was used widely in high voltage apparatus. $\mathrm{SF}_{6}$ is a direct source of carbon emissions from the power grid. $\mathrm{SF}_{6}$ emissions can be reduced by applying $\mathrm{SF}_{6}$ recovery and utilization technology, or by finding alternative gas, and developing new technologies and so on.

Under the supply chain carbon management, grid connects power generators and consumers, serve and promote carbon emission reduction of generation side and consumer side. Firstly, the distribution of wind, solar, hydropower and other clean energy resources in China are relatively concentrated, which have the conditions for large-scale and intensive development, the grid provides a strong transmission channel for large-scale and long distances transmission for clean power, promote clean energy scale development. Secondly, By the means of optimizing energy generation scheduling, the generations with different energy types, economic and environmental performance will be dispatched in the widest scope possible, the utilization rate of cleaner and more efficient generations will rise, and emissions will be minimized as possible. Thirdly, carrying out power generation right transaction, which replaces small power plants with bigger ones and replaces thermal power plants with hydropower plants, could help to reduce energy consumption and emissions. With the expansion of the trading range, it will bring more low-carbon benefits. Fourthly, power grid corporation provide strong and firm support for the development of electric vehicles. Electric vehicles use electricity instead of gasoline, and release almost no $\mathrm{CO}_{2}$ and air pollutants at the place where they are operated. In addition, the low-carbon benefits of electric vehicles will come from wider range of load adjusting, promoting the power supply system more stable and efficient[6]. Fifthly, grid will interconnect more distributed energies, and make them widely used possible. At the same time, distributed generation reduces the amount of energy lost in transmitting electricity because the electricity is generated very near where it is used, and may give lower 
environmental impacts. Lastly, power grid corporation need to strengthen Demand Side Management (DSM). DSM will be enhanced by popularizing energy saving, load adjustment technology and demand-side management projects construction, optimizing power consumption mode, increasing efficiency of end users, and assisting the high energy-consuming industries, such as metallurgy, mining, petrochemical etc. to reduce their power consumption.

Taking SGCC as a case study, this paper evaluates the benefits of carbon emission reduction of SGCC by supply chain carbon management in2010. Compared with 2009, carbon reduction benefits of SGCC in 2010 are 137.7 million tons. In 2010, the line loss has been lowered which was equivalent to reduce 3.5 million tons $\mathrm{CO}_{2}, 1.5$ million tons $\mathrm{CO}_{2}$ was reduced by recovery and substitution of sulfur hexafluoride $\left(\mathrm{SF}_{6}\right)$. 77.4 million tons $\mathrm{CO}_{2}$ was reduced by promoting the development of clean energy sources, which is the largest source of emission reduction. The low-carbon benefit resulting from power generation right transaction was about 35.0 million tons. The carbon reduction benefit resulting from energy-saving generation dispatch was about 10.1 million tons. 10.2 million tons of $\mathrm{CO}_{2}$ was reduced by DSM. With the development of electric vehicles, 0.014 million tons $\mathrm{CO}_{2}$ was reduced. Promoting the development of clean energy and demand side response are most important functions of SGCC in promoting low-carbon development all the time. The key reason is that the grid is a green platform to promote intensive development of clean energy, and enhance the communication and interaction between the grid and consumers as well as improving system performances and service quality.

\section{Power grid corporation's carbon management under the development of carbon market}

With the development of China's carbon market, when large-scale carbon trading to carry out, in bringing significant opportunities, it also has a significant impact on the aspects of construction, plan, operation and management. Firstly, Carbon trading will bring power grid corporation significant opportunities to accelerate technology and management innovation. Grid corporation will try hard to reduce power transmission and distribution losses, that will contribute to construct smart grid, optimize network structure, develop UHV transmission technology, and so on[6]. Secondly, the carbon market will promote the development of wind, solar, hydropower and other clean energy resources, which were relatively concentrated and far away from the the load centers, large-scale and long distances transmission for clean energy and promoting their scale development. The grid will be request to provide a strong transmission channel for large-scale and long distances transmission for clean power, promote clean energy scale development. Thirdly, in order to adapt to various kinds of low-carbon power's rapid development under the carbon market environment, the dispatch of grid is requested to be more controllable, safety, flexible and robust. With the construction of UHV power grids and national network interconnection, large-scale generation dispatch aimed at energy saving and environmental protection will come true.

Power grid corporation need to change strategy and management models based on the new situation, and strengthen capacity building of carbon emission statistics, carbon asset management, low-carbon technology innovation and enterprise carbon management.

Firstly, strengthen capabilities of carbon emissions statistics, monitoring and management. Carbon emission statistics, verification and reporting are most important basic work for any one company . Therefore, power grid corporation need to strengthen the statistics and management of carbon emissions data, and establish a complete data collection, accounting and management system, which may provide support for participate in the carbon market and implement carbon emission reduction.

Secondly, strengthen capabilities of carbon asset management. With the development of the 
domestic carbon trading, particularly the introduction of carbon finance, the contents and methods of carbon asset management will be broaden a lot, and may bring some new profit growth points. So, power grid corporation need pay attention to and strengthen capacity building of carbon asset management, such as the development, reserves and evaluation of carbon asset, market strategy, investment analysis and other aspects.

Thirdly, strengthen the low-carbon technology innovation and $\mathrm{R} \& \mathrm{D}$ capabilities. In order to decreased the costs of emission reduction and get more space for development, the key is to carry out technological innovation. For power grid corporation, network technology of large-scale renewable energy, advanced energy storage, smart grid, ultra-high voltage grid and so on need to be further enhanced.

Fourthly, strengthen capacity building of enterprise carbon management. when grid corporation develop the strategic planning, it should consider the carbon emissions constraints, study the development strategies and investment plans under the carbon market environment, taking into account the impact of carbon prices ,carbon asset management and other issues. Carbon emissions reduction and carbon emissions trading will throughout the whole process that include planning, investment, construction, technical innovation, operation and management of power companies. So, it need to set up establish a management system, and strengthen coordination and cooperation of the business sector to enhance corporate carbon management.

\section{Conclusions}

China's future development is clearly trending toward low-carbon growth, China will face a number of challenges in achieving its INDC targets. Grid plays a pivotal and irreplaceable role in reducing carbon emission during energy production, transmission, consumption, etc. The supply chain carbon management of power grid corporation is mainly reflected in two aspects. One is the emissions reduction potential can achieve by itself, such as reducing transmission and distribution losses and recovery and substitution of sulfur hexafluoride $\left(\mathrm{SF}_{6}\right)$. Another is the emissions reduction potential that can be achieved by cooperation with the generations and customers in the supply chain, such as promoting clean energy scale development, promoting the development of electric vehicles and distributed energy resources, strengthening Demand Side Management (DSM), and so on. Promoting the development of clean energy and demand side response are most important contents of the supply chain carbon management of power grid corporation.

\section{References}

[1] Guo Yin, Wang Minjie, Low Carbon Economy's Situation and Trend in Global, Ecological Economy, 11(2009) 58-61.

[2] Information on http://www.ncsc.org.cn/article/yxcg/ir/201507/20150700001490.shtml.

[3] Wu peng, Jiang liping, Comprehensive benefits evaluation of smart grid. China Power Enterprise Management. 7(2009)35-37.

[4] State Grid Energy Research Institute. Analysis of carbon emission reduction potential and methodology research for SGCC, Beijing, 2011.

Fu liwen, Analysis on Low-carbon benefits of Smart Grid, Electric Power Construction, 32(2011)51-55.

[5] State Grid Corporation of China. 2011Corporate Social Responsibility Report of State Grid Corporation of China, Beijing, 2011.

[6] State Grid Energy Research Institute, Strong and smart grid in promoting low carbon development, Beijing, 2010. 